\title{
Em defesa de uma sociedade sem manicômios: disputas e ameaças frente ao recrudescimento do projeto neoliberal
}

\author{
In defense of a society without asylums: disputes and threats in \\ the face of the resurgence of the neoliberal agenda
}

Elisa Zaneratto Rosa

Pontifícia Universidade Católica de São Paulo. São Paulo, São Paulo, Brasil. ORCID: 0000-0003-2263-6889. elisazrosa@pucsp.br

Os debates sobre as ameaças e retrocessos em relação às conquistas do campo da saúde mental, provocadas pela política de Reforma Psiquiátrica no recente período democrático e impulsionadas pelo movimento da luta antimanicomial, tem ganhado centralidade diante do conjunto de medidas que expressam a retirada de direitos pela guinada neoliberal assumida no projeto político em curso no país. A centralidade desse debate deve-se ao modo como as medidas que apontam ao desmonte do Sistema Único de Saúde (SUS) e de outras políticas de garantia de direitos, ao lado daquelas que apontam para o fortalecimento de políticas de extermínio e opressão da parcela da população que historicamente representa as mazelas resultantes dos mecanismos de manutenção das desigualdades, insistem em eleger modelos, programas e políticas do campo da saúde mental como um de seus focos.

A disputa em torno do projeto que defendemos pela perspectiva antimanicomial não é recente. Ela acompanha o curso do neoliberalismo no Brasil que, por sua vez, convive com a implementação do próprio SUS e das conquistas da Constituição de 1988, caracterizando limitações e contradições enfrentadas ao longo dos 30 anos de sua trajetória. Na história da Reforma Psiquiátrica tal disputa se expressa na dificuldade de sustentação da radicalidade antimanicomial na política implementada, observada em processos como: a lentidão progressiva para o fechamento de leitos em hospitais psiquiátricos financiados pelo SUS no último período de Reforma; a regulamentação de novas modalidades de instituições manicomiais pelo poder público, por meio do financiamento de comunidades terapêuticos no campo da atenção em álcool e outras drogas; o enfraquecimento do debate sobre a manutenção dos hospitais psiquiátricos e a permanência de moradores nessas instituições em convivência com a implementação da rede substitutiva; um certo recuo do movimento social em relação à crítica contundente à gestão de uma política pública de saúde mental em seus pontos frágeis, que incluem a pactuação com modelos de gestão que não favorecem a qualificação do trabalho na rede de atenção psicossocial a partir de uma perspectiva antimanicomial; o distanciamento cotidiano entre o debate do movimento antimanicomial, desestabilizador 
do campo teórico, técnico, assistencial, institucional, político e ético, que sustenta a abordagem da loucura pelos contornos da doença mental, e o cotidiano dos serviços que compõem a rede substitutiva ao hospital psiquiátrico; a dificuldade de fortalecer os dispositivos de atenção à saúde mental, para além dos serviços especializados, na rede de atenção à saúde e pelas políticas intersetoriais.

Esses processos conviveram com a intensidade que, por outro lado, representou a possibilidade de implementação de uma Reforma Psiquiátrica no Brasil, movimentada por uma luta de trabalhadores e usuários marcada pela alegria, pela aposta na diversidade e pela defesa intransigente do valor de todas as vidas. Assim, diante do cenário de desigualdade, pobreza e crise internacional do modelo universalista de Estado social (SPOSATI, 2008), o Brasil empreendeu uma profunda mudança na assistência à saúde mental.

Desde as primeiras experiências emblemáticas no campo da Reforma, como a criação do primeiro Centro de Atenção Psicossocial na cidade de São Paulo, em 1987, e a primeira grande intervenção e fechamento de um Hospital Psiquiátrico realizada na cidade de Santos/SP, em 1989, passando pela aprovação da Lei 10.216 de 2001 e pela realização de quatro conferências nacionais de saúde mental, empreendemos complexas operações de fechamento de leitos psiquiátricos, acompanhadas pela abertura e regulação de novos serviços, pela criação de muitos dispositivos e pela invenção cotidiana de novas estratégias de cuidado. Indicando o descredenciamento e fechamento de cerca de 60 mil leitos em hospitais psiquiátricos desde o início do processo de Reforma Psiquiátrica, a última publicação pelo Ministério da Saúde do informativo eletrônico Saúde Mental em Dados (BRASIL, 2015) apontava 2.209 CAPS em atuação, 610 Serviços Residenciais Terapêuticos, 34 Unidades de Acolhimento, 111 equipes de consultório na rua e mais 888 leitos de saúde mental em Hospitais Gerais. No início da década atual, a porcentagem dos gastos com serviços extra-hospitalares passou a ser a mesma relativa aos gastos com hospitais psiquiátricos dez anos atrás. Como parte do projeto de descentralização da assistência e do reconhecimento do papel estratégico da Atenção Básica para o cuidado territorializado em saúde mental, havia em 2015 uma cobertura populacional estimada em cerca de $60 \%$ quanto à implementação de equipes da Estratégia Saúde da Família, com o total de 3898 Núcleos de Apoio à Saúde da Família, os quais empreendem esforços cotidianos no acompanhamento dos casos de saúde mental no território, de forma articulada à rede especializada de saúde mental (ROSA, 2016).

Desde o final do ano de 2015, no entanto, quando começam a se concretizar mudanças que acenavam para a instabilidade do governo da presidenta eleita Dilma Roussef e mais contundentemente com as medidas que seguiram após o golpe que levou à sua destituição, empreendem-se uma série de ações que confluem para o desmonte do SUS, com especial ênfase numa mudança de perspectiva em relação à política e aos modelos de atenção à saúde mental, em contraposição aos princípios que orientaram a Reforma Psiquiátrica Antimanicomial. Em dezembro de 2015, pela primeira vez desde o início do processo de implementação do SUS, o Ministério da Saúde nomeia um Coordenador Nacional de Saúde Mental, Álcool e outras Drogas - Valencius Wurch - que historicamente esteve contrário ao processo da Reforma Psiquiátrica, com uma trajetória sem adesão ao movimento social e ao campo de produção de novos modelos conceituais e assistenciais pelo qual foi fomentada.

Seguindo uma breve retrospectiva, já no âmbito do governo Michel Temer, um ano após a aprovação da Emenda Constitucional do Teto de Gastos Públicos e pouco tempo depois da aprovação de uma nova Política Nacional de Atenção Básica, em dezembro de 2017, logo após o Encontro de comemoração dos 30 anos de Luta Antimanicomial em Bauru, a Comissão Intergestores Tripartite, de forma autoritária, sem diálogo com os movimentos sociais e ignorando a construção histórica das diretrizes da política de saúde mental pelos processos de participação e controle social, aprovou uma reformulação da Rede de Atenção Psicossocial. Seguiram uma série de posicionamentos pela reorientação no campo da atenção em álcool e outras drogas, por meio dos quais o governo federal assume sua adesão ao modelo da abstinência e o fortalecimento da política proibicionista. Por fim, cumpre salientar que no início de 2019 
o governo Jair Bolsonaro lança uma Nota Técnica na qual afirma como "nova" uma Política de Saúde Mental que, sistematizando as mudanças previstas pelas portarias do governo golpista, recoloca na diretriz da política de saúde mental dispositivos como os ambulatórios, a eletroconvulsoterapia, além do próprio hospital psiquiátrico e de outras modalidades de serviços manicomiais de atenção para usuários de álcool e outras drogas, as comunidades terapêuticas. Mais recentemente, a mudança do financiamento da Atenção Básica aponta para o fim da universalidade do SUS e para a ruptura com modelos de atenção que foram essenciais à descentralização e à territorizalização do cuidado em saúde mental.

Para além das reorientações assumidas pelo governo federal, mas não independente delas, na medida em que legitimam posições contrárias ao horizonte ético político que movimenta a perspectiva antimanicomial na atenção, no cuidado e no plano das relações, da convivência social e da cultura, vimos sustentado a resistência pelo fazer cotidiano nos diversos espaços onde trabalhadores, usuários, gestores e familiares insistem numa perspectiva de defesa da vida em sua diversidade, tendo como horizonte a superação das desigualdades. No entanto, fato é que o ataque à política de saúde mental nesse momento histórico significa muito mais do que o desmonte de uma rede de serviços de atenção e acesso a direitos, assim como o projeto antimanicomial significa uma ousadia muito além da implantação de uma Rede de Atenção Psicossocial, embora equivocadamente, em algum momento, tenha ficado identificado a ela.

A perspectiva antimanicomial aponta para um outro projeto civilizatório. O movimento da luta antimanicomial orienta-se pelo direito à igualdade a partir do reconhecimento da diversidade. Combate práticas e instituições manicomiais, entendendo-as como aquelas que, por meio de mecanismos mais ou menos sofisticados de categorização, empregam coerção, violência e anulação dos sujeitos, destituindo-os de sua cidadania e, em última medida, eliminando-os. Tendo a liberdade como causa e consequência, o projeto antimanicomial recusa qualquer forma de negação e opressão da diferença (SILVA, 2005). Se tomarmos como referência o Manifesto de Bauru de 1987, que marca a fundação do movimento antimanicomial, encontramos muito mais que a radical ruptura com um modelo de assistência em saúde mental. Encontramos um compromisso com a revisão dos elementos presentes na cultura e na relação da sociedade de um modo mais geral com a loucura, por meio da explicitação de seus determinantes estruturais. Assim, a carta afirma a recusa às instituições por meio das quais o Estado assume o papel de agente da exclusão e da violência e o denuncia pelos mecanismos de exploração e de produção social da loucura. Ao fazer isso, enlaça o movimento antimanicomial com o movimento popular e com a classe trabalhadora organizada, denunciando o manicômio como uma estrutura, presente na opressão das fábricas, nas instituições voltadas aos adolescentes, no encarceramento e na discriminação contra negros, homossexuais, índios, mulheres. Situa a luta pelos direitos de cidadania das pessoas consideradas loucas como a luta dos trabalhadores pelo direito à saúde, justiça e melhores condições de vida.

Assim, o ataqueà Reforma Psiquiátrica Antimanicomial nesse momento de barbárie, em que o capitalismo demonstra o esgotamento das possibilidades de sua continuidade, assumindo a face do extermínio bem expressa nas posições que hoje identificamos como fascistas e que acompanham, nos discursos e posições assumidas pelo governo brasileiro, como componente ideológico, as medidas econômicas e sociais necessárias à recuperação do capital, é muito mais do que o desmonte de uma rede de atenção em saúde. $O$ ataque à Reforma Psiquiátrica é o ataque ao caldo antimanicomial que representou sua faceta mais potente, sua originalidade e sua radicalidade.

$\mathrm{O}$ ataque dirige-se à ousadia de nosso projeto, que reside em seu horizonte ético: a aposta em novas formas de produção da vida social, a partir do reconhecimento das desigualdades estruturantes dessa sociedade e do acolhimento à diversidade que dela resulta, para além da aceitação pautada pela defesa da liberdade desses sujeitos. Sobre isso, Basaglia (2010) nos provoca à contradição que reside no projeto de socializar o desvio e a marginalidade, quando sua característica constitutiva está na privação de bens e do poder contratual, apontando que nosso 
projeto é de transformação social. Assim, em sua radicalidade antimanicomial, a Reforma Psiquiátrica brasileira representou uma política pública potente ao processo histórico de transformação social e, nessa leitura, aí reside o foco do ataque sofrido.

Nesse sentido, é preciso que sejamos firmes na posição a partir da qual vamos lutar e resistir. Nossa luta nesse momento, mais do que pela defesa de portarias, redes e modelos de serviços, é a luta que novamente se reconhece pela defesa da vida daqueles que estão no alvo do projeto de extermínio em curso pelo esgotamento das possibilidades civilizatórias no âmbito dessas relações de produção. Nessa direção, é preciso resgatar o sentido antimanicomial da Reforma Psiquiátrica para defendê-la como política pública, o que significa reconhecer que nosso compromisso é com a população pobre e negra, com os povos indígenas, com a dignidade das mulheres que lutam cotidianamente pela sua sobrevivência e pela vida das suas crianças. Significa identificar que o cuidado que operamos na rede de atenção em saúde mental compõe as estratégias para o fortalecimento desses sujeitos diante do sofrimento que a eles se impõem diariamente pelos mecanismos de opressão e violência a que estão submetidos. Significa lembrarmos que ser parceiros da loucura, como tantas vezes afirmamos, é andar de mãos dadas com essa parcela da população, valorizando suas vidas. Significa trabalhar no plano da conquista afetiva em defesa da solidariedade e da justiça social, assumindo que transformar a posição manicomial no plano da cultura e das relações sociais é engajar-se na transformação da naturalização das desigualdades estruturais que perseguem nossa história, a qual caracteriza o racismo, o machismo, a homofobia, o preconceito de classe e todas as formas de intolerância produzidas por nossa história e nunca superadas. São esses antigos processos, hoje legitimados, que caracterizam o que identificamos como um novo fascismo na sociedade brasileira. A luta antimanicomial compõe esse campo e é preciso resgatarmos e afirmarmos isso para enfrentarmos coletivamente e com a alegria que marca a nossa história os desafios que esse tempo coloca para nós.

\section{Referências}

Basaglia, F. (2010). O circuito do controle: do manicômio à descentralização psiquiátrica. In: AMARANTE, P. (org.). Escritos selecionados em saúde mental e reforma psiquiátrica. Rio de Janeiro: Garamond.

Ministério da Saúde. (2015). Saúde Mental em Dados. Ano 10, n. 12. Brasília. Recuperado de https://www.mhinnovation. net/sites/default/files/downloads/innovation/reports/ Report_12-edicao-do-Saude-Mental-em-Dados.pdf

Ministério da Saúde. (2005). Secretaria de Atenção à Saúde. Departamento de Ações Programáticas Estratégicas. Saúde mental e economia solidária: inclusão social pelo trabalho / Ministério da Saúde, Secretaria de Atenção à Saúde, Departamento de Ações Programáticas e Estratégicas. Brasília: Editora do Ministério da Saúde. Recuperado de http://www.ee.usp.br/departamento/nucleo/CComs/doc/ Sm\%20e\%20economia\%20solid\%E1 ria.pdff

Rosa, E. Z. (2016). Por uma Reforma Psiquiátrica Antimanicomial: o papel estratégico da Atenção Básica para um projeto de transformação social (Tese de doutorado). Pontifícia Universidade Católica, Programa de Estudos PósGraduados em Psicologia Social. São Paulo, SP, Brasil. Recuperado de https://tede2.pucsp.br/handle/ handle/18816

Sposati, A. (2008). Implementação de programas sociais: conflitos e tensões metodológicas na América Latina. In: C. C. Arregui, \& D. N. Blanes (orgs.). Metodologias do trabalho social. São Paulo: IEE/PUC 